Prepared for the U.S. Department of Energy

under Contract DE-AC05-76RL01830

\title{
Simulating Collisions for Hydrokinetic Turbines. FY2010 Annual Progress Report
}

MC Richmond

CL Rakowski

WA Perkins

JA Serkowski

November 2010

Pacific Northwest

NATIONAL LABORATORY

Proudly Operated by Battelle Since 1965 


\title{
DISCLAIMER
}

This report was prepared as an account of work sponsored by an agency of the United States Government. Neither the United States Government nor any agency thereof, nor Battelle Memorial Institute, nor any of their employees, makes any warranty, express or implied, or assumes any legal liability or responsibility for the accuracy, completeness, or usefulness of any information, apparatus, product, or process disclosed, or represents that its use would not infringe privately owned rights. Reference herein to any specific commercial product, process, or service by trade name, trademark, manufacturer, or otherwise does not necessarily constitute or imply its endorsement, recommendation, or favoring by the United States Government or any agency thereof, or Battelle Memorial Institute. The views and opinions of authors expressed herein do not necessarily state or reflect those of the United States Government or any agency thereof.

\author{
PACIFIC NORTHWEST NATIONAL LABORATORY \\ operated by \\ BATTELLE \\ for the \\ UNITED STATES DEPARTMENT OF ENERGY \\ under Contract DE-AC05-76RL01830
}

Printed in the United States of America
Available to DOE and DOE contractors from the Office of Scientific and Technical Information,
P.O. Box 62, Oak Ridge, TN 37831-0062;
ph: (865) 576-8401
fax: $(865) 576-5728$
email: reports@adonis.osti.gov

\footnotetext{
Available to the public from the National Technical Information Service, U.S. Department of Commerce, 5285 Port Royal Rd., Springfield, VA 22161 ph: (800) 553-6847 fax: $(703) 605-6900$ email: orders@ntis.fedworld.gov online ordering: http://www.ntis.gov/ordering.htm
}

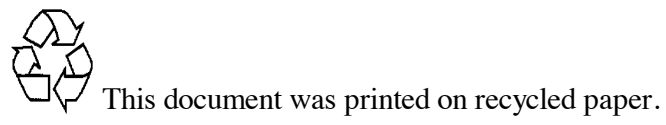




\title{
Simulating Collisions for Hydrokinetic Turbines. FY2010 Annual Progress Report
}

\author{
MC Richmond \\ CL Rakowski \\ WA Perkins \\ JA Serkowski
}

November 2010

Prepared for

the U.S. Department of Energy

under Contract DE-AC05-76RL01830

Pacific Northwest National Laboratory

Richland, Washington 99352 



\begin{abstract}
Computational fluid dynamics (CFD) simulations of turbulent flow and particle motion are being conducted to evaluate the frequency and severity of collisions between marine and hydrokinetic (MHK) energy devices and debris or aquatic organisms. The work is part of a collaborative research project between Pacific Northwest National Laboratory (PNNL) and Sandia National Laboratories (SNL), funded by the U.S. Department of Energy Office of Energy Efficiency and Renewable Energy Wind and Water Power Program. During FY2010 a reference design for an axial flow MHK turbine was used to develop a computational geometry for inclusion into a CFD model. Unsteady simulations of turbulent flow and the moving MHK turbine blades are being performed and the results used for simulation of particle trajectories. Preliminary results and plans for future work are presented.
\end{abstract}





\section{Acknowledgments}

Support for this research was provided by the U.S. Department of Energy, Office of Energy Efficiency and Renewable Energy - Wind and Water Power Program. The work reported here is part of a collaborative research project with Sandia National Laboratories. The authors would like to thank Matthew Barone of Sandia National Laboratories for providing the turbine geometry. 



\section{Contents}

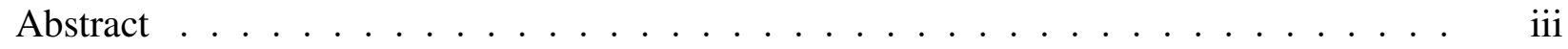

Acknowledgments ........................ . . . .

1.0 Introduction . . . . . . . . . . . . . . . . . . . . . . . . . . . . 1

2.0 Computational Methods $\ldots \ldots \ldots \ldots$

2.1 CFD Code $\ldots \ldots \ldots \ldots \ldots \ldots$

2.2 MHK Turbine Geometry . . . . . . . . . . . . . . . . . . . 3

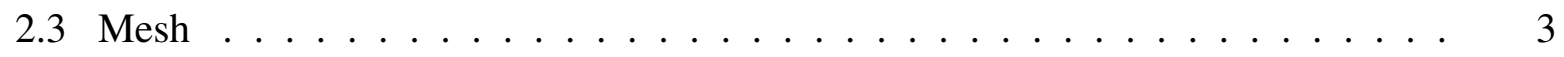

2.4 Simulation Conditions . . . . . . . . . . . . . . . . . . 4

2.5 Lagrangian Particle Tracking . . . . . . . . . . . . . . . . . . 4

3.0 Results . . . . . . . . . . . . . . . . . . . . . . . . 7

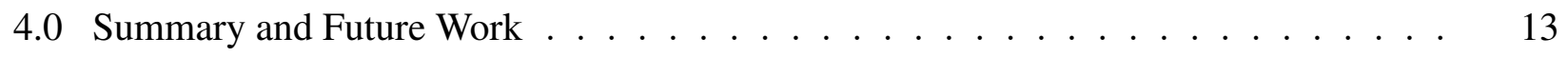

5.0 References . . . . . . . . . . . . . . . . . . . . . . . 15 


\section{Figures}

$2.1 \quad$ MHK turbine geometry. Dimensions are in meters. . . . . . . . . . . . . . . 4

2.2 Computational domain showing turbine and multiple zones of mesh refinement. The turbine is oriented in a downstream configuration where the inflow boundary is at the left side of the figure. . . . . . . . . . . . . . . . .

$2.3 \quad$ Mesh near turbine showing zones of increased resolution on the surfaces. . . . . . . 6

3.1 Streamlines showing the partially developed transient flowfield at a single instant in time. . . . . . . . . . . . . . . . . . .

$3.2 \quad$ Velocity iso-surface at a magnitude of $2.35 \mathrm{~m} / \mathrm{s}$ at a single instant in time. . . . . . 8

3.3 Velocity magnitude for downstream (left column) and side views (right column) at three different instances in time showing the effect of the rotor motion. . . . . . .

3.4 Pressure distribution for downstream (left column) and side views (right column) at three different instances in time showing the effect of the rotor motion. . . . . . . 10

3.5 Examples of the particle cloud moving from the upstream release plane towards and past the turbine. Each graphic shows a single instant in time. Tracks are colored by particle velocity. . . . . . . . . . . . . . . . . 11

3.6 Examples of some individual particle tracks that collide with the turbine rotor blades. Tracks are colored by particle velocity. 


\subsection{Introduction}

Evaluations of biological performance, for example strike/collision, for marine and hydrokinetic (MHK) turbines are important because they will affect the machine design through changes that strive to maximize machine performance while minimizing the frequency and severity of strike. Experience with conventional hydro turbines (Dauble et al.2007) has shown that innovative shaping of the blade and other machine components can lead to improved designs that generate more power without increased impacts to fish and other aquatic life.

The objective of this project is to develop a predictive modeling tool that can provide statistical distributions of strike/collision frequency, severity, and location for specific MHK designs using outputs from computational fluid dynamics (CFD) simulations.

This report presents a summary of the computational methodology and its application to a reference axial flow MHK design during FY2010. Plans for future work in FY2011 are also presented. 



\subsection{Computational Methods}

\subsection{CFD Code}

The CFD code used in this work is Starccm+ (version 5.04.006, cd-adapco 2010). Starccm+ and its sister code, Star-CD, have been used by Pacific Northwest National Laboratory (PNNL) for conventional hydropower applications for over 10 years. Starccm + solved the three-dimensional unsteady Reynolds-averaged Navier-Stokes equations (URANS) together with the $k-\varepsilon$ turbulence model. Standard wall functions were used for boundary conditions on the MHK turbine surfaces and seabed. The momentum equations were solved using 2 nd order methods for space and first order methods for time advancement. The unsteady simulations were carried out using a parallel computing cluster at PNNL. The unsteady CFD model output was archived for later use by the Lagrangian particle tracking code.

\subsection{MHK Turbine Geometry}

The MHK turbine geometry was developed starting from a preliminary reference model design for an axial flow machine provided by Matt Barone of Sandia National Laboratories (Barone 2010). The MHK turbine design was targeted for an ambient inflow speed of $2 \mathrm{~m} / \mathrm{s}$ and water depth of $20 \mathrm{~m}$. A constant rotation speed of $3.2 \mathrm{rad} / \mathrm{s}(30.6 \mathrm{rpm})$ was selected. The turbine operates in downstream configuration where the rotor blades are downstream of the support tower. This is opposite of typical horizontal axis wind turbines that operate in an upwind configuration.

The design parameters were used to construct a solid geometry model using SolidWorks computer aided design (CAD) software (Dessault Systemes Version Professional 2009 SP0.0). The resulting MHK turbine is shown in Figure 2.1.

\subsection{Mesh}

The solid geometry file was imported into Starccm+ where a surface and volume mesh were created. For these preliminary simulations, the turbine was placed in a flow domain that was $52 \mathrm{~m}$ long in the streamwise direction, $20 \mathrm{~m}$ wide, and $20 \mathrm{~m}$ deep in the vertical direction. An unstructured, trim cell mesh was created using the the Starccm+ meshing tools. An attractive feature of trim cell meshes is that the cell type is predominately hexahedral throughout the domain. Approximately 4.7 million computational cells are in the mesh. The mesh distribution is non-uniform to provide a balance between coarser resolution far from the machine (Figure 2.2) and higher resolution on the surface to capture boundary layers (Figure 2.3).

Future simulations will need to have a longer streamwise distance to capture the machine wake, but for initial testing purposes a smaller domain was chosen to reduce the computational resource requirements. 


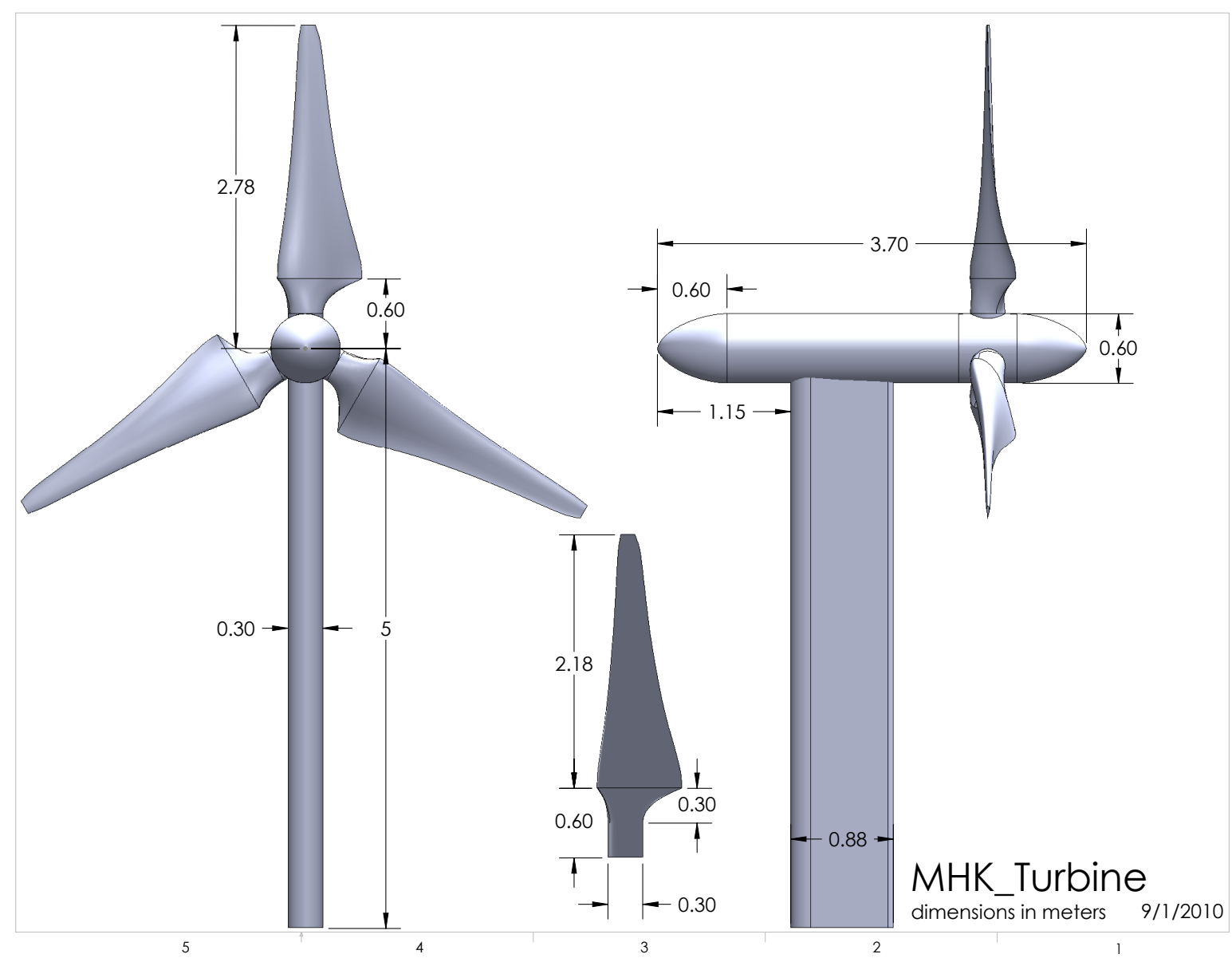

Figure 2.1. MHK turbine geometry. Dimensions are in meters.

\subsection{Simulation Conditions}

A uniform velocity of $2 \mathrm{~m} / \mathrm{s}$ was specified at the upstream inflow boundary. The water surface (top boundary) and lateral boundaries were represented as a symmetry planes. An outflow boundary was used at the downstream end of the domain. The seabed and turbine surfaces were specified as walls and standard wall functions were assigned. A time step of $0.001 \mathrm{~s}$ was used for the moving mesh simulations.

\subsection{Lagrangian Particle Tracking}

The CFD results were used with a Lagrangian particle tracking code developed at PNNL. Particles can experience hydrodynamic forces and torques that are defined, for example, by drag coefficients, lift coefficients, buoyancy, etc. This allows for the simulation of the trajectories of spheroidal and non-spheroidal particles. The tracking code can simulate paths for particles both with and without mass (streamlines). The particle tracking uses the velocity and turbulence fields simulated from the CFD code. The particles were 4-cm diameter spheres with a specific gravity of 1 (neutrally buoyant). In the initial tests documented here, a set of 1000 particles were 
released upstream of the MHK turbine and tracked through a single time slice from the transient CFD simulation.

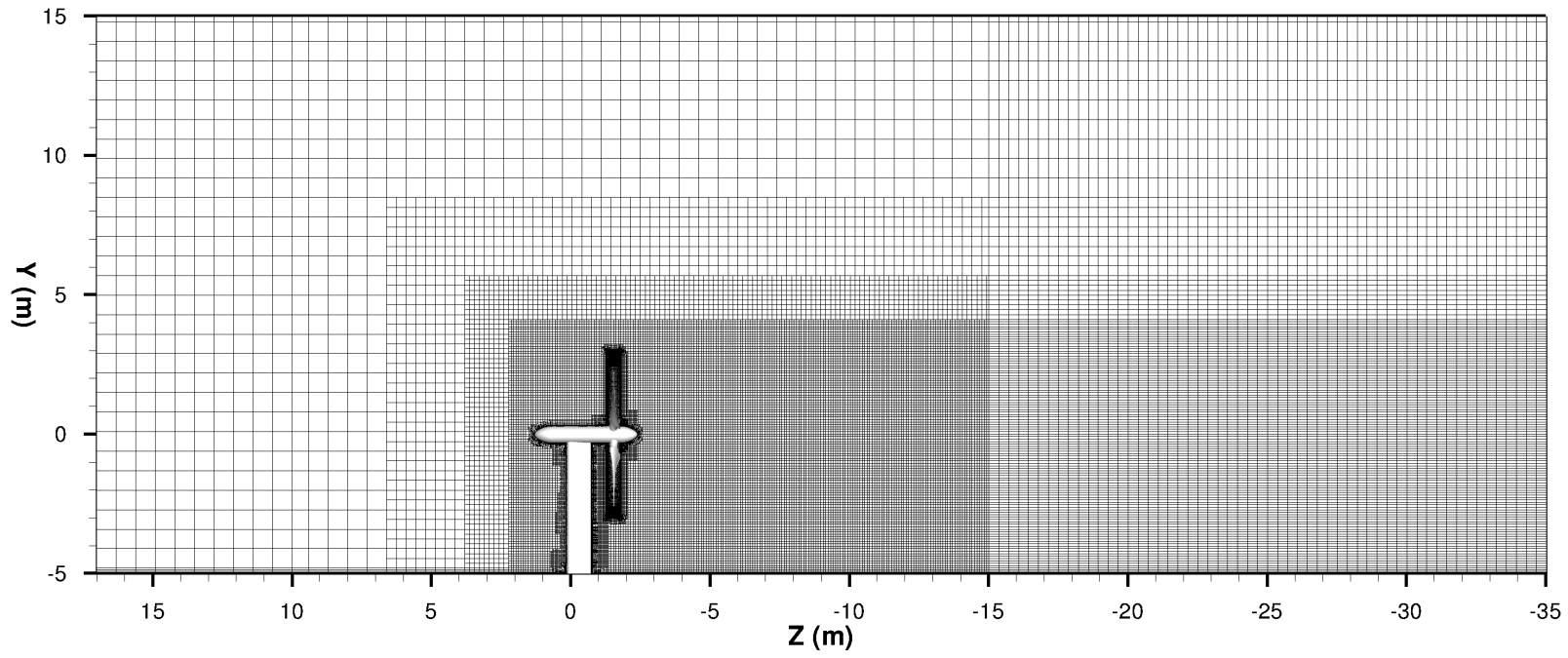

Figure 2.2. Computational domain showing turbine and multiple zones of mesh refinement. The turbine is oriented in a downstream configuration where the inflow boundary is at the left side of the figure. 


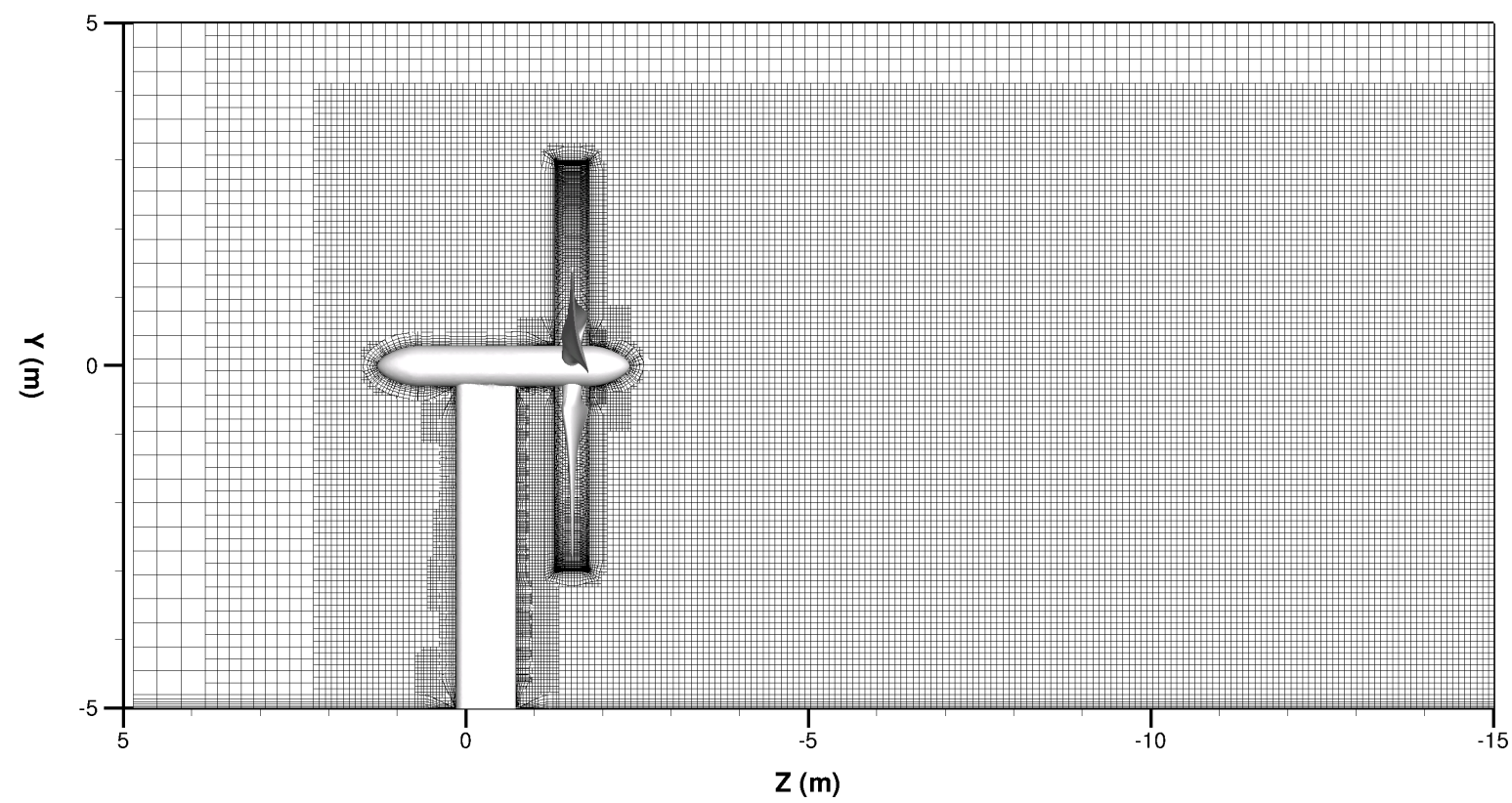

Figure 2.3. Mesh near turbine showing zones of increased resolution on the surfaces. 


\subsection{Results}

At the time of the preparation of this report, the transient simulations are still in progress. However, the preliminary simulation results are now available that can be used to test and demonstrate the various components of the collision simulation methodology.

The general characteristics of the flowfield at a single instant in time are shown by streamlines and a velocity iso-surface in Figures 3.1 and 3.2, respectively.

The transient velocity magnitude and pressure fields are shown for multiple time instances in Figures 3.3 and 3.4 , respectively. Tip vortices can be seen advecting downstream from the blades into the near wake. Notice the zones of shear (velocity gradients) and of low and rapidly changing pressures. These are additional physical stressors that are potentially damaging to aquatic organism in addition to blade collision.

The capability of the tracking code to simulate particle trajectories through the unstructured trim mesh was tested. A total of 1000 particles were released upstream of the turbine and tracked through the domain (Figure 3.5). A few sample collisions with the rotor blades are shown in Figure 3.6. Note that in these preliminary test simulations the particles are tracked in a single time slice from the transient solution. This can cause some particle paths to interact with the rotor blade in ways that will not occur in the final application, which will use a completely transient flowfield. Despite this limitation, some of the particle-rotor interactions indicate the presence of flow separation zones. This indicates that the turbine geometry and operating parameters may need to be examined since flow separation will have an adverse effect on machine performance. 




Figure 3.1. Streamlines showing the partially developed transient flowfield at a single instant in time.

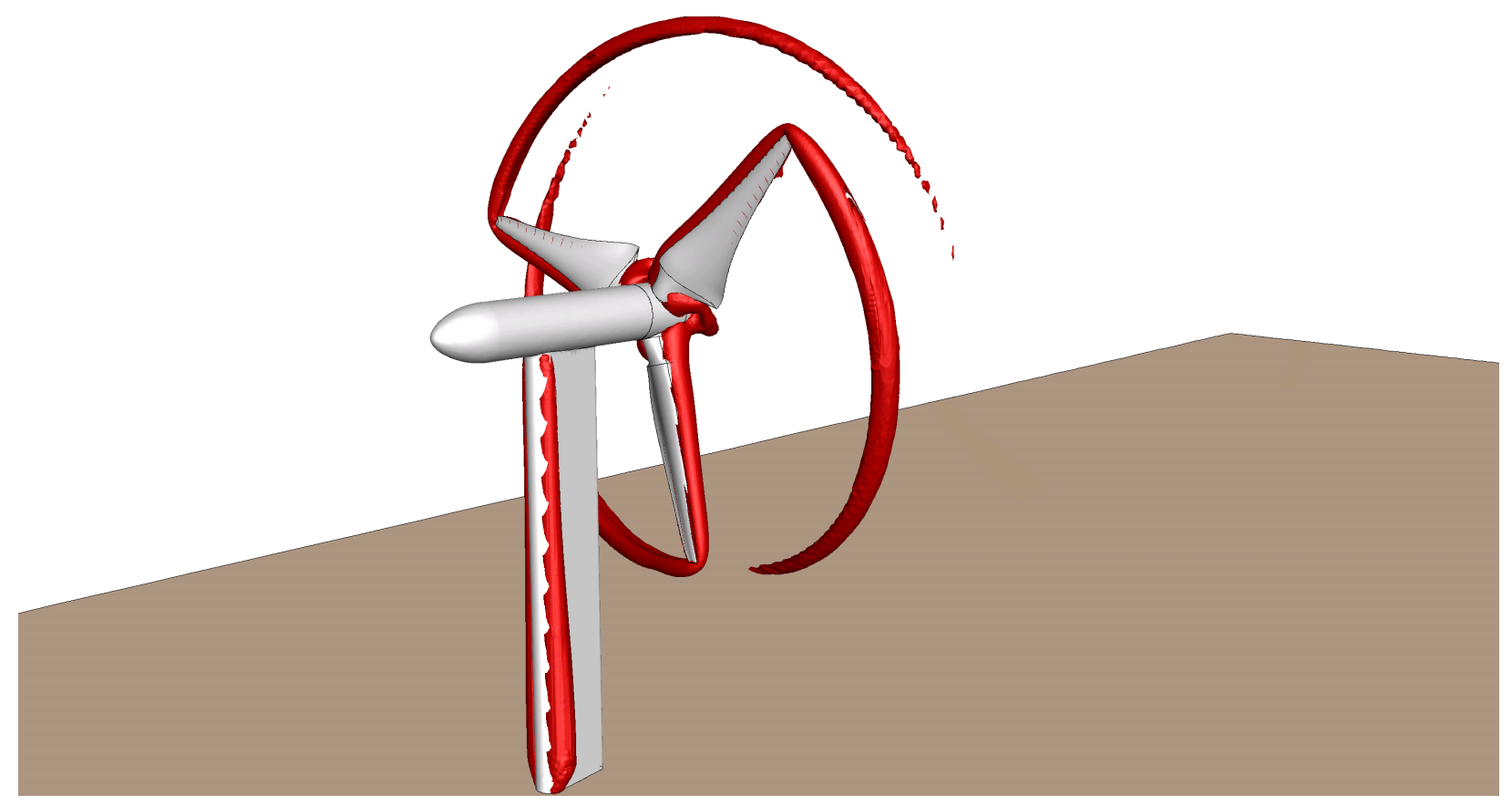

Figure 3.2. Velocity iso-surface at a magnitude of $2.35 \mathrm{~m} / \mathrm{s}$ at a single instant in time. 



Figure 3.3. Velocity magnitude for downstream (left column) and side views (right column) at three different instances in time showing the effect of the rotor motion. 

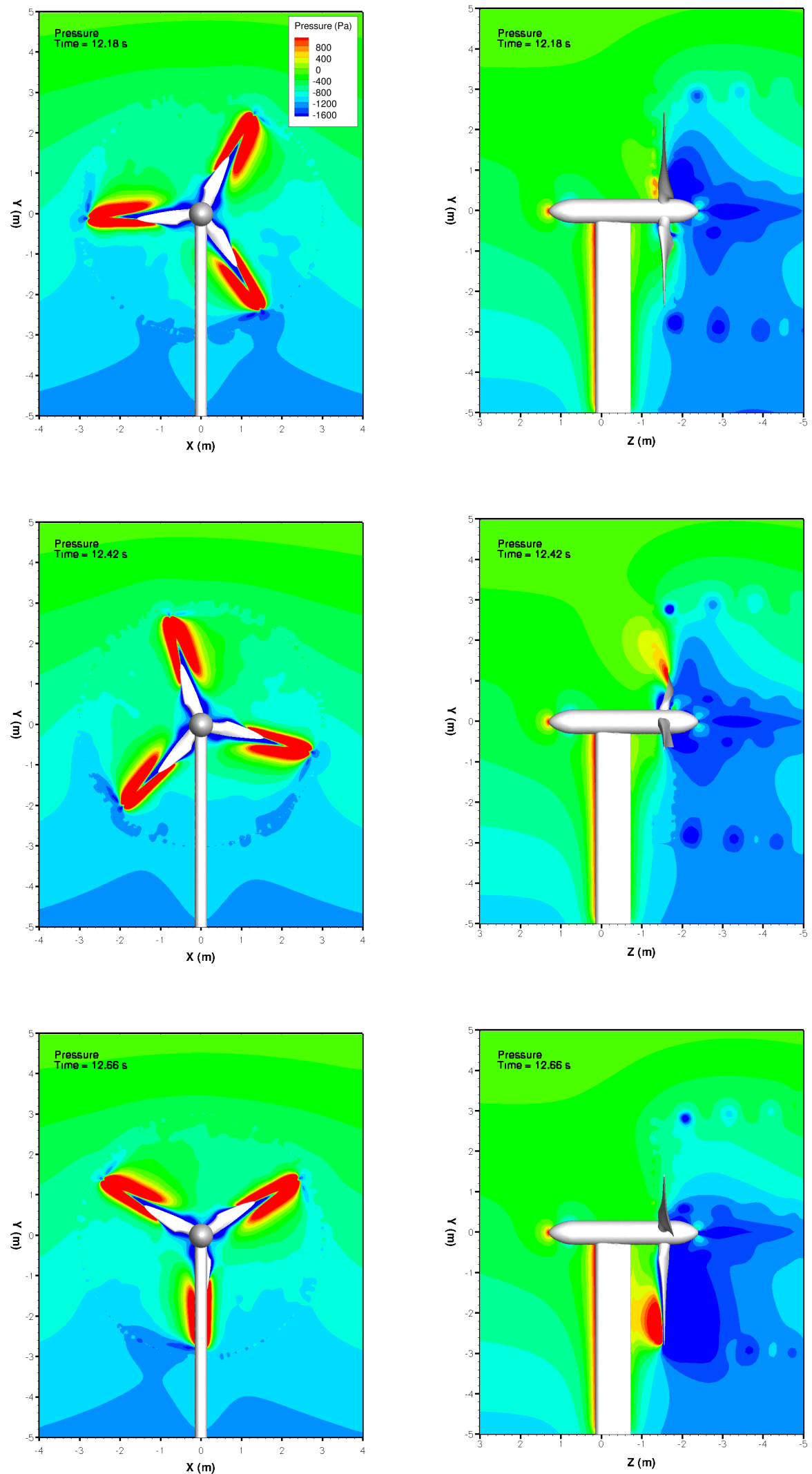

Figure 3.4. Pressure distribution for downstream (left column) and side views (right column) at three different instances in time shboving the effect of the rotor motion. 

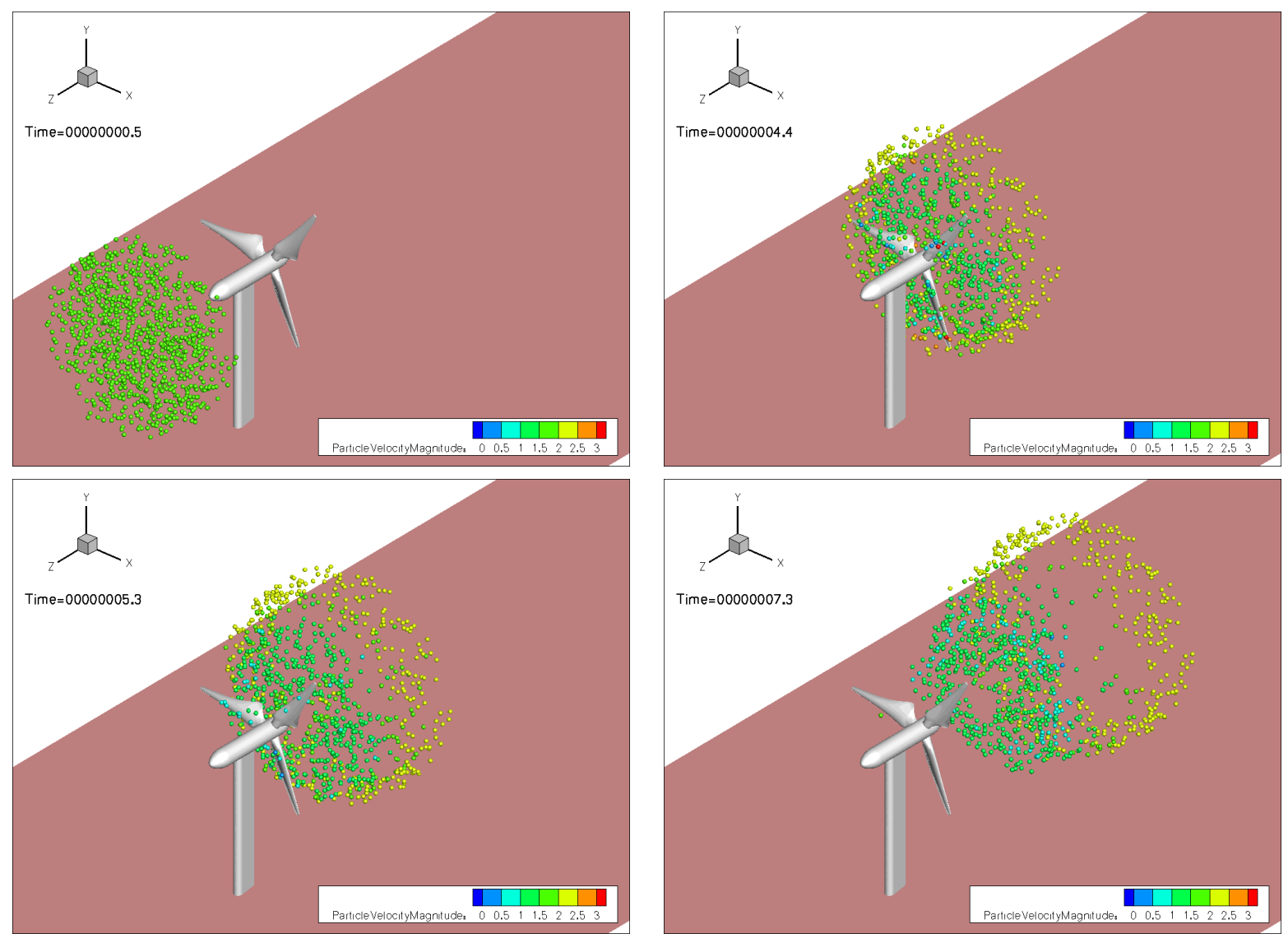

Figure 3.5. Examples of the particle cloud moving from the upstream release plane towards and past the turbine. Each graphic shows a single instant in time. Tracks are colored by particle velocity. 

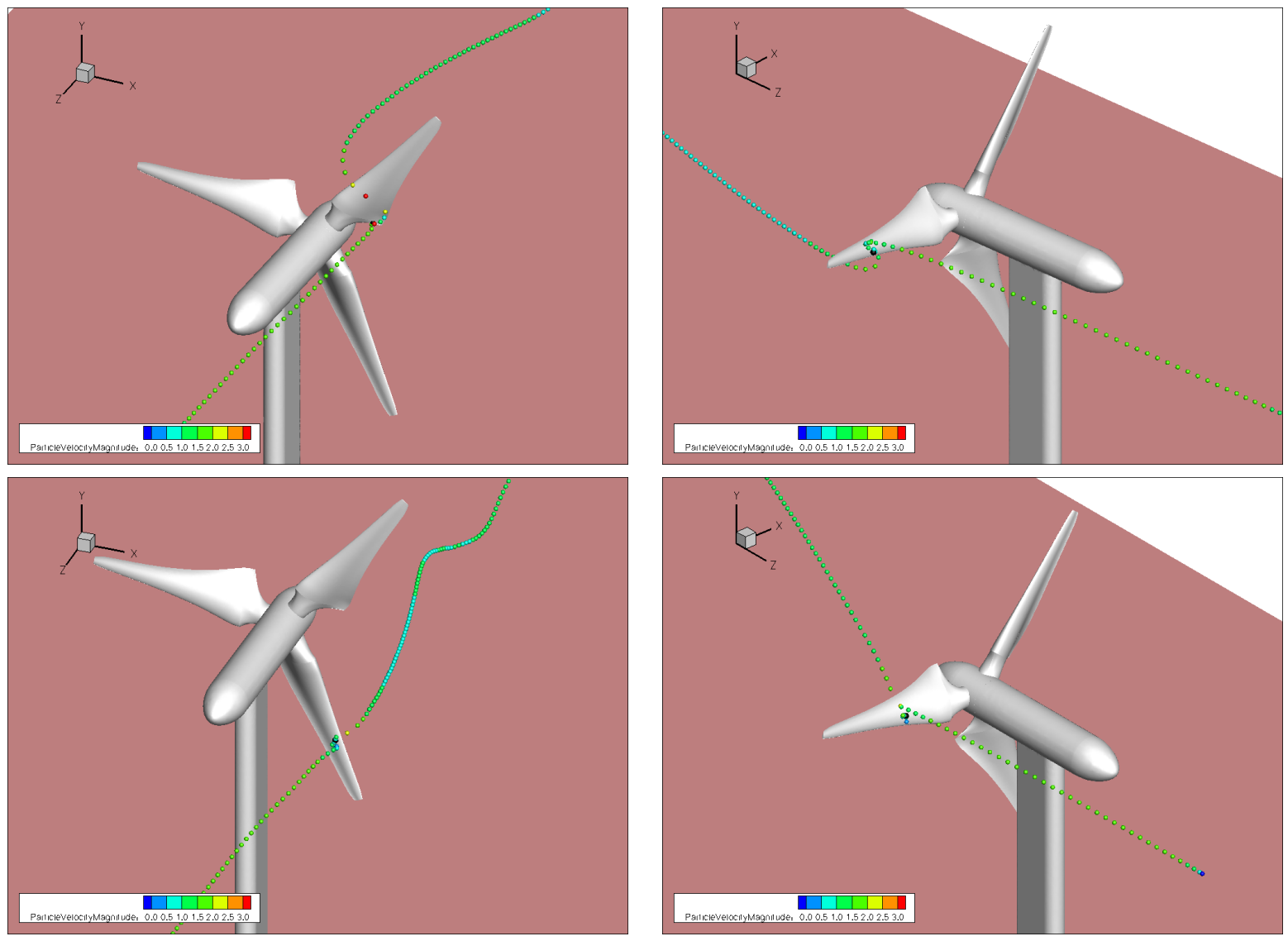

Figure 3.6. Examples of some individual particle tracks that collide with the turbine rotor blades. Tracks are colored by particle velocity. 


\subsection{Summary and Future Work}

A reference model geometry for an axial flow MHK device suitable for modeling with a CFD code was developed and used in a transient simulation. The preliminary results indicate that the computational methodology consisting of the CFD and particle tracker codes are able to represent the complex flow features induced by the moving MHK turbine blades. The simulations will need to continue and allow the flow field to evolve after which a more complete particle tracking analysis will be done to characterize the statistical distributions of strike/collision frequency, severity, and location.

During FY11 we plan to continue the work in the following areas:

- refine the axial flow MHK turbine geometry and operating parameters in collaboration with Sandia National Laboratories to extract turbine performance information in addition to the collision calculations

- develop a geometry and perform simulations for a cross-flow MHK device and compare to the axial flow device

- investigate computational tradeoffs such as using the multiple frame of reference approximation that would require less computing time at the sacrifice of some fidelity

- examine the sensitivity of the results to different methods of representing fluid turbulence on the computation of the flowfield and particle trajectories 



\subsection{References}

Barone M. 2010. Preliminary Design of a Reference Marine Hydrokinetic Turbine. Sandia National Laboratories.

cd-adapco. 2010. User Guide, STAR-CCM+ Version 5.04.006. CD-adapco, http://www.cdadapco.com.

Dauble D, Z Deng, M Richmond, R Moursund, T Carlson, C Rakowski, and J Duncan. 2007.

Biological Assessment of the Advanced Turbine Design at Wanapum Dam, 2005. PNNL-16682, Pacific Northwest National Laboratory. 



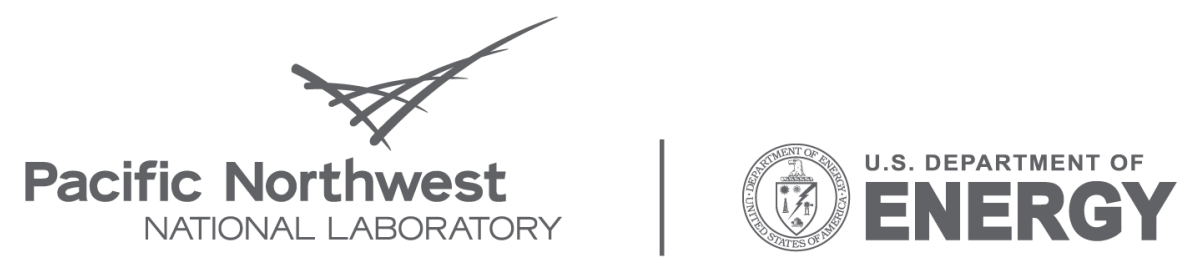

Proudly Operated by Battelle Since 1965

902 Battelle Boulevard

P.O. Box 999

Richland, WA 99352

1-888-375-PNNL (7665)

www.pnl.gov 